\title{
Impact of Undetected Comorbidity on Treatment and Outcomes of Breast Cancer
}

\author{
Robert I. Griffiths, ${ }^{1,2}$ Michelle L. Gleeson, ${ }^{3}$ José M. Valderas, ${ }^{1}$ and Mark D. Danese ${ }^{3}$ \\ ${ }^{1}$ Nuffield Department of Primary Care Health Sciences, University of Oxford, 23-38 Hythe Bridge Street, 2nd Floor, \\ Oxford OX1 2ET, UK \\ ${ }^{2}$ Division of General Internal Medicine, Johns Hopkins University School of Medicine, Baltimore, MD 21205, USA \\ ${ }^{3}$ Outcomes Insights, 340 North Westlake Blvd, Suite 200, Westlake Village, CA 91362, USA
}

Correspondence should be addressed to Robert I. Griffiths; robert.griffiths@conted.ox.ac.uk

Received 10 October 2013; Accepted 6 January 2014; Published 13 February 2014

Academic Editor: Ian S. Fentiman

Copyright (C) 2014 Robert I. Griffiths et al. This is an open access article distributed under the Creative Commons Attribution License, which permits unrestricted use, distribution, and reproduction in any medium, provided the original work is properly cited.

\begin{abstract}
Preexisting comorbidity adversely impacts breast cancer treatment and outcomes. We examined the incremental impact of comorbidity undetected until cancer. We followed breast cancer patients in SEER-Medicare from 12 months before to 84 months after diagnosis. Two comorbidity indices were constructed: the National Cancer Institute index, using 12 months of claims before cancer, and a second index for previously undetected conditions, using three months after cancer. Conditions present in the first were excluded from the second. Overall, 6,184 (10.1\%) had $\geq 1$ undetected comorbidity. Chronic obstructive pulmonary disease $(38 \%)$ was the most common undetected condition. In multivariable analyses that adjusted for comorbidity detected before cancer, older age, later stage, higher grade, and poor performance status all were associated with higher odds of $\geq 1$ undetected comorbidity. In stage I-III cancer, undetected comorbidity was associated with lower adjusted odds of receiving adjuvant chemotherapy (Odds Ratio $(\mathrm{OR})=0.81,95 \%$ Confidence Interval $(\mathrm{CI}) 0.73-0.90, P<0.0001$; OR $=0.38,95 \%$ CI $0.30-0.49, P<0.0001$; index score 1 or $\geq 2$, respectively), and with increased mortality (Hazard Ratio (HR) $=1.45,95 \%$ CI 1.38-1.53, $P<0.0001 ; \mathrm{HR}=2.38,95 \%$ CI 2.18-2.60, $P<0.0001$; index score 1 or $\geq 2$ ). Undetected comorbidity is associated with less aggressive treatment and higher mortality in breast cancer.
\end{abstract}

\section{Introduction}

Comorbidity adversely impacts the treatment [1-7] and outcomes $[1,3,6,8-22]$ of breast cancer, especially in older patients. For instance, studies have shown that breast cancer patients with previously identified comorbidity are less likely to receive adjuvant chemotherapy $[2,4,5]$ and have higher mortality [8]. Many such studies from the United States are based on the Surveillance, Epidemiology, and End Results cancer registry linked to health insurance claims (SEERMedicare) $[1,2,5,6,17-20]$, where a common approach is first to identify conditions appearing in claims prior to cancer and then to use these conditions to construct a National Cancer Institute (NCI) Comorbidity Index [23], which is an adaptation of the Charlson index (CCI) [24].

Most studies based on SEER-Medicare include some measures of comorbidity, and in a random sample of all
SEER-Medicare studies published between 2006 and 2011, 23/30 (77\%) included the NCI Comorbidity Index. One important limitation of this index, however, is that it ignores conditions that are undetected in claims until after cancer is diagnosed. Recently, we examined the incidence of undetected comorbidity in breast cancer [25] and found that many chronic conditions included in the NCI Comorbidity Index, such as chronic obstructive pulmonary disease (COPD), congestive heart failure (CHF), diabetes, and cerebrovascular disease (CVD), remained undetected in claims until 1-3 months after cancer.

Undetected comorbidity could have additional implications for breast cancer treatment and outcomes. Therefore, in this study we sought to describe risk factors for comorbidity that remained undetected until breast cancer, and to assess the added impact of undetected comorbidity on breast cancer treatment and outcomes. 


\section{Methods}

2.1. Data. Presently SEER-Medicare [26] includes all Medicare-eligible persons from 16 of the 17 SEER registries through 2005 and their Medicare claims for Part A (inpatient) and Part B (outpatient and physician services) through 2007.

2.2. Patients. Patients were included if they were diagnosed with breast cancer between 2001-01-01 and 2005-12-31, had only one primary cancer diagnosed, and had at least 12 months of Medicare Part A and Part B coverage prior to cancer. They were excluded for the following reasons: male breast cancer, cancer diagnosed before age 65, diagnosis made by death certificate or autopsy, death within the first month following diagnosis, or Medicare enrollment less than 12 months before diagnosis. Patients were followed up from 12 months before cancer until the end of the claims period (200712-31) or death, whichever came first. Since SEER reports only the month of cancer diagnosis, the first day of that month was assigned as the date of diagnosis.

2.2.1. Variables. Patients were described according to their demographic, clinical, and socioeconomic characteristics $[26,27]$. SEER does not include measures of performance status, such as Eastern Cooperative Oncology Group. Instead, we used Medicare claims to identify several indictors of poor performance status, including the use of oxygen and related respiratory therapy supplies, wheelchair and supplies, home health agency services, and skilled nursing facility admissions, all from 12 months before until 30 days after breast cancer diagnosis [28].

The SEER-Medicare dataset contains information from the 2000 US Census, reported at the tract level in which the patient lives, for the percent of the population living in poverty and the percent of those aged $\geq 25$ years with some college. We used these as indicators of the socioeconomic status of individual patients in the cohort.

2.2.2. Comorbidity. We constructed two indices of comorbidity. In SEER-Medicare, the gold standard for documenting the presence of comorbidity prior to cancer is the NCI Comorbidity Index [23], which is usually constructed based on claims from 12 months to one month before cancer diagnosis. Diagnosis and procedure codes are used to identify the 15 noncancer comorbidities in the CCI [24]. A weight is then assigned to each condition, and the weights are summed to obtain the index score for each patient. We followed this approach to capture comorbidity detected prior to cancer and classified patients as having a score $=0,1$, or $\geq 2$.

We applied the same algorithms used in the NCI Comorbidity Index to construct an index of undetected comorbidity, which was based on claims from the month of cancer diagnosis up to two months after. For each patient, conditions identified prior to cancer were excluded from the undetected comorbidity index. If chemotherapy or radiation began within three months following cancer diagnosis, the observation period for the undetected comorbidity index was truncated at that time to minimize the risk of misclassifying treatment-related adverse events as undetected conditions. As above, patients were classified as having a score $=0,1$, or $\geq 2$. Since the minimum weight assigned to any condition in either index is one (1), for clarity the term " $\geq 1$ condition/ comorbidity" is used in the Results to describe patients with a score on either the previously detected or undetected comorbidity index of $\geq 1$.

2.2.3. Adjuvant Chemotherapy. Adjuvant chemotherapy was identified based on Healthcare Common Procedure Coding (HCPCS) "J" codes as recommended by the NCI [29]. The first claim for chemotherapy had to appear within 180 days of cancer diagnosis for the patient to be classified as having received chemotherapy.

2.3. Mortality. The date of death was assigned by using the Medicare date if available. When the Medicare date was missing but the SEER date was available, the SEER date was used. All other patients were assumed to be alive at the end of the observation period. The cause of death was classified as cancer or other cause.

2.4. Statistical Analysis. Multivariable analyses were performed to examine risk factors for undetected comorbidity, as well as associations between undetected comorbidity, adjuvant chemotherapy, and mortality. Both indices of comorbidity were included in analyses of treatment and mortality to assess the incremental impact of undetected comorbidity. The multivariable analysis of adjuvant chemotherapy was limited to those with stage I-III disease [5]. All multivariable survival analyses included only those who survived at least 3 months after cancer diagnosis. Final models were selected through a process of forward, stepwise regression, taking into account statistical significance, interactions among covariables, and whether a nonstatistically significant finding was informative. In almost all instances, at least one level of each variable included in the final model was statistically significantly different from the reference category of that variable. In all instances, prior comorbidity and previously undetected comorbidity were included in the final multivariable model. However, we compared the magnitude and significance of the coefficients on the previously undetected comorbidity in models that included versus excluded prior comorbidity as a covariable to assess the level of colinearity between these two.

\section{Results}

There were 61,002 patients in the final cohort, of whom 6,184 (10\%) had $\geq 1$ undetected comorbidity. The mean (standard deviation) age was 76.0 (6.8), 54.6\% were aged $>75$ years, $61 \%$ were diagnosed with in situ or stage I disease, $14 \%$ had $\geq 1$ indicator of poor performance, and $33 \%$ had $\geq 1$ comorbidity detected prior to cancer (Table 1). Those with $\geq 1$ undetected comorbidity also were more likely to have $\geq 1$ condition detected prior to cancer. 
TABle 1: Patient characteristics.

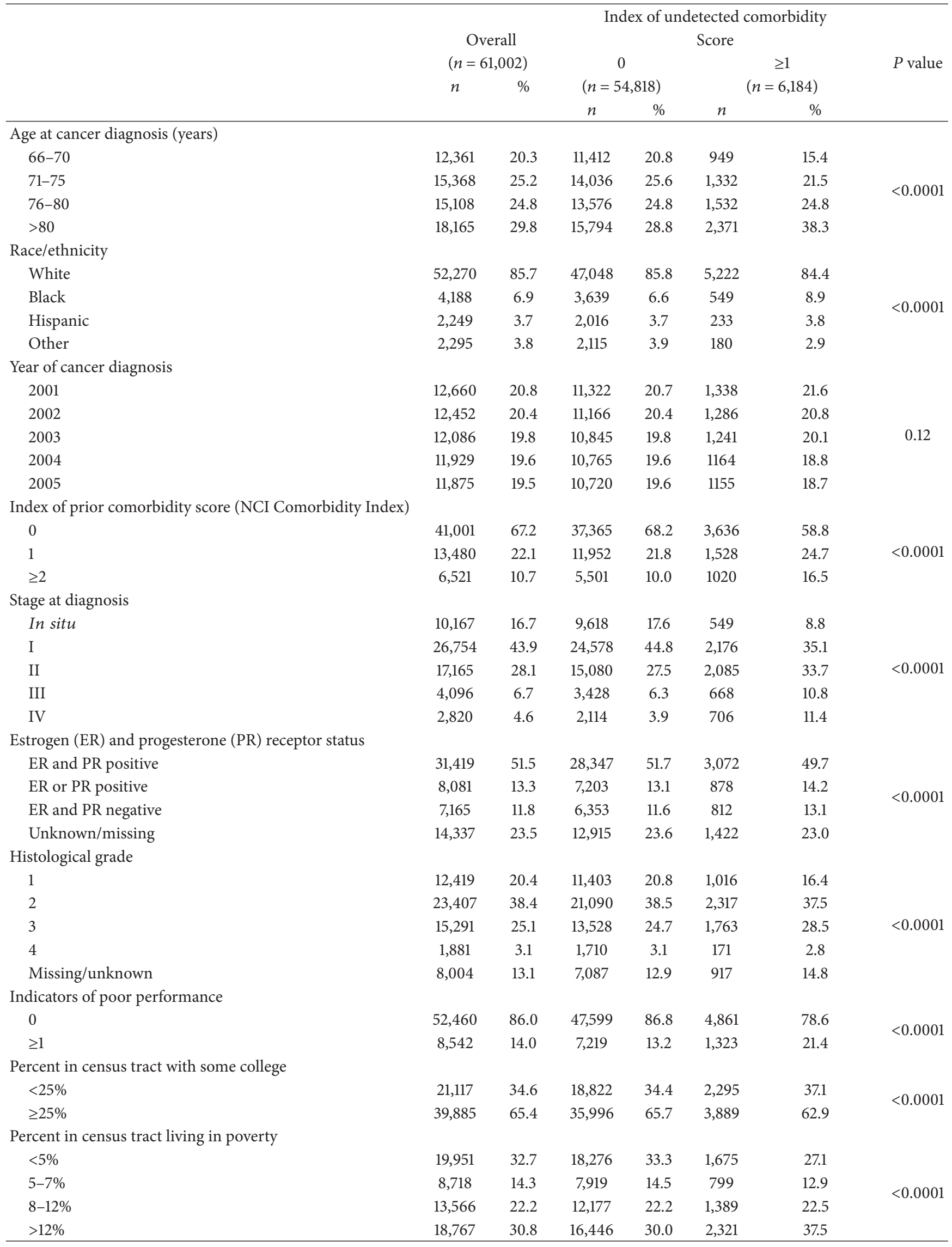


TABLE 1: Continued.

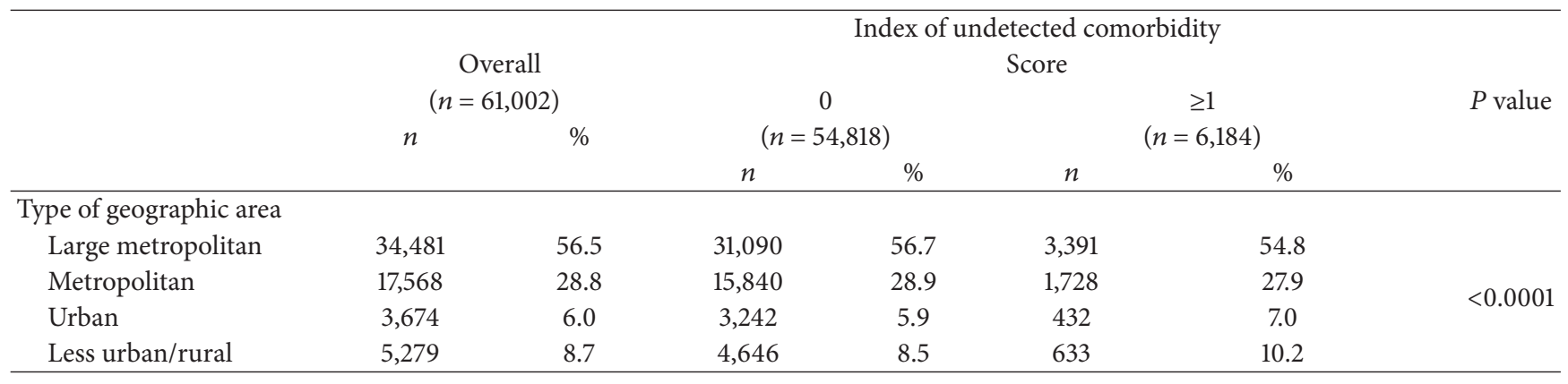

3.1. Undetected Comorbidity. Among the 6,184 patients with $\geq 1$ undetected comorbidity, there were a total of 7,593 conditions. The most common were COPD $(33 \%[2,023 / 6,184]$ of patients), CHF (18\%), diabetes (18\% without complications; $4 \%$ with complications), myocardial infarction (14\%), and CVD (10\%). In multivariable logistic regression, factors associated with having $\geq 1$ undetected condition were older age, $\geq 1$ comorbidity detected prior to cancer, $\geq 1$ indicator of poor performance status, advanced stage, histological grade, living in a census tract with more poverty, and living in an urban area. Other race/ethnicity (compared to white) and later year of cancer diagnosis were associated with lower odds of having $\geq 1$ undetected condition (Table 2).

3.2. Chemotherapy. In multivariable analysis, undetected comorbidity was associated with lower adjusted odds of receiving adjuvant chemotherapy (Odds Ratio $(\mathrm{OR})=0.81$, 95\% Confidence Interval (CI) 0.73-0.90, $P<0.0001$; OR = $0.38,95 \%$ CI $0.30-0.49, P<0.0001$, for undetected comorbidity index score 1 or $\geq 2$, resp.) (Table 3 ). Other factors associated with lower odds were older age, later year of diagnosis, having $\geq 2$ conditions detected prior to cancer, being either estrogen and/or progesterone receptor positive, and living in a census tract with $>12 \%$ poverty. Factors associated with higher odds included advanced stage and higher grade.

3.3. Survival. Overall, there were 13,208 (22\% of cohort) deaths: 5,191 (39\% of all deaths) due to cancer; 5,823 (44\%) due to other causes; and (17\%) unspecified. Among those with $\geq 1$ undetected comorbidity, $42 \%(2,575)$ died during the observation period compared to $19 \%(10,633)$ of those with no undetected conditions, and the unadjusted mortality rate was significantly higher $(P<0.0001)$ (Figure 1$)$.

In multivariable survival analysis, having undetected comorbidity was associated with increased all-cause mortality (Hazard Ratio $(\mathrm{HR})=1.45,95 \%$ CI 1.38-1.53, $P<0.0001$; $\mathrm{HR}=2.38,95 \%$ CI 2.18-2.60, $P<0.0001$, for undetected comorbidity index score 1 or $\geq 2$, resp.), cancer mortality (HR $=1.32$ and $\mathrm{HR}=1.67$ for score 1 or $\geq 2$ ), and other-cause mortality $(H R=1.58$ and $H R=3.31$ for score 1 or $\geq 2)$ (Table 4$)$. In most instances, coefficients for undetected comorbidity were comparable to or larger than those for comorbidity detected prior to cancer.
3.4. Models with versus without Previously Detected Comorbidity. There was little difference in the magnitude and significance of the coefficients for the previously undetected comorbidity for multivariable models that included versus excluded prior comorbidity as a covariable. For instance, the coefficients for the chemotherapy model were 0.80 and 0.37 for undetected comorbidity scores of 1 and $\geq 2$, respectively, in the model that excluded prior comorbidity compared to 0.81 and 0.38 in the model that included prior comorbidity (Table 3).

\section{Discussion}

We conducted an observational cohort study using SEERMedicare to describe risk factors for comorbidity that remained undetected until breast cancer and to assess the added impact of undetected comorbidity on breast cancer treatment and outcomes. Advanced age, later stage diagnosis, poor performance status, presence of comorbidity identified prior to cancer, and poverty all were associated with increased risk of undetected comorbidity. The strong monotonic association with cancer stage, as well as the association with poverty, suggests the existence of shared risk factors, such as poor health system contact prior to cancer diagnosis, [30, 31] resulting in delayed detection of both cancer and other underlying chronic conditions including COPD, CHF, and diabetes. One important implication of our study is that those with other established risk factors for poor outcomes in breast cancer, including advanced age, later stage, and poor performance status, also are at greatest risk for undetected comorbidity.

Patients with undetected comorbidity were less likely to receive adjuvant chemotherapy. Furthermore, the effect sizes were larger for undetected comorbidity than for comorbidity detected prior to cancer. For example the Odds Ratio for an undetected comorbidity index score $\geq 2$ was 0.38 compared to 0.74 for a score $\geq 2$ on the index of conditions prior to cancer. Since identification of conditions was based on claims for medical services, one hypothesis is that undetected conditions were more severe because they had not been treated. Others have speculated that one way comorbidity can influence treatment and outcomes in cancer is by distracting the healthcare team from the appropriate management of both 
TABLE 2: Risk of undetected comorbidity.

\begin{tabular}{|c|c|c|c|c|}
\hline & \multirow{2}{*}{ OR } & \multicolumn{2}{|c|}{$95 \% \mathrm{CI}$} & \multirow{2}{*}{$P$ value } \\
\hline & & Lower & Upper & \\
\hline \multicolumn{5}{|l|}{ Age at cancer diagnosis (years) } \\
\hline $66-70$ & \multicolumn{4}{|c|}{ Reference category } \\
\hline $71-75$ & 1.12 & 1.02 & 1.22 & 0.02 \\
\hline $76-80$ & 1.28 & 1.17 & 1.39 & $<0.0001$ \\
\hline$>80$ & 1.53 & 1.41 & 1.66 & $<0.0001$ \\
\hline \multicolumn{5}{|l|}{ Race/ethnicity } \\
\hline White & \multicolumn{4}{|c|}{ Reference category } \\
\hline Black & 1.04 & 0.94 & 1.16 & 0.41 \\
\hline Hispanic & 0.94 & 0.81 & 1.08 & 0.39 \\
\hline Other & 0.83 & 0.71 & 0.97 & 0.02 \\
\hline \multicolumn{5}{|l|}{ Year of cancer diagnosis } \\
\hline 2001 & \multicolumn{4}{|c|}{ Reference category } \\
\hline 2002 & 0.99 & 0.91 & 1.07 & 0.75 \\
\hline 2003 & 0.98 & 0.90 & 1.07 & 0.68 \\
\hline 2004 & 0.93 & 0.85 & 1.01 & 0.08 \\
\hline 2005 & 0.92 & 0.84 & 1.00 & 0.05 \\
\hline \multicolumn{5}{|c|}{ Index of prior comorbidity score (NCI Comorbidity Index) } \\
\hline 0 & \multicolumn{4}{|c|}{ Reference category } \\
\hline 1 & 1.20 & 1.13 & 1.28 & $<0.0001$ \\
\hline$\geq 2$ & 1.50 & 1.38 & 1.63 & $<0.0001$ \\
\hline \multicolumn{5}{|l|}{ Indicators of poor performance } \\
\hline 0 & \multicolumn{4}{|c|}{ Reference category } \\
\hline$\geq 1$ & 1.30 & 1.21 & 1.40 & $<0.0001$ \\
\hline \multicolumn{5}{|l|}{ Stage at diagnosis } \\
\hline In situ & \multicolumn{4}{|c|}{ Reference category } \\
\hline I & 1.66 & 1.49 & 1.85 & $<0.0001$ \\
\hline II & 2.40 & 2.15 & 2.67 & $<0.0001$ \\
\hline III & 3.26 & 2.87 & 3.71 & $<0.0001$ \\
\hline IV & 5.51 & 4.85 & 6.26 & $<0.0001$ \\
\hline \multicolumn{5}{|l|}{ Histological grade } \\
\hline Well differentiated & \multicolumn{4}{|c|}{ Reference category } \\
\hline Moderately differentiated & 1.11 & 1.02 & 1.20 & 0.01 \\
\hline Poorly differentiated & 1.15 & 1.05 & 1.26 & $<0.01$ \\
\hline Undifferentiated/anaplastic & 1.25 & 1.05 & 1.50 & 0.01 \\
\hline Missing/unknown & 1.14 & 1.03 & 1.27 & 0.01 \\
\hline \multicolumn{5}{|c|}{ Estrogen (ER) and progesterone (PR) receptor status } \\
\hline ER and PR negative & \multicolumn{4}{|c|}{ Reference category } \\
\hline ER or PR positive & 1.05 & 0.94 & 1.16 & 0.39 \\
\hline ER and PR positive & 1.00 & 0.92 & 1.09 & 1.00 \\
\hline Unknown/missing & 1.14 & 1.03 & 1.27 & 0.01 \\
\hline Percent in census tract with sor & & & & \\
\hline$<25 \%$ & & & egory & \\
\hline$\geq 25 \%$ & 0.99 & 0.93 & 1.05 & 0.70 \\
\hline Percent in census tract living in & & & & \\
\hline$<5 \%$ & & & egory & \\
\hline $5-7 \%$ & 1.07 & 0.98 & 1.17 & 0.12 \\
\hline $8-12 \%$ & 1.17 & 1.08 & 1.27 & $<0.0001$ \\
\hline$>12 \%$ & 1.34 & 1.25 & 1.45 & $<0.0001$ \\
\hline Type of geographic area & & & & \\
\hline Large metropolitan & & & egory & \\
\hline Metropolitan & 0.97 & 0.91 & 1.04 & 0.42 \\
\hline Urban & 1.14 & 1.02 & 1.28 & 0.02 \\
\hline Less urban/rural & 1.09 & 0.99 & 1.20 & 0.08 \\
\hline
\end{tabular}

OR: Odds Ratio; CI: Confidence Interval. 
TABle 3: Adjuvant chemotherapy.

\begin{tabular}{|c|c|c|c|c|}
\hline & \multirow{2}{*}{ OR } & \multicolumn{2}{|c|}{$95 \% \mathrm{CI}$} & \multirow{2}{*}{$P$ value } \\
\hline & & Lower & Upper & \\
\hline \multicolumn{5}{|l|}{ Age at cancer diagnosis (years) } \\
\hline $66-70$ & \multicolumn{4}{|c|}{ Reference category } \\
\hline $71-75$ & 0.55 & 0.51 & 0.59 & $<0.0001$ \\
\hline $76-80$ & 0.25 & 0.23 & 0.27 & $<0.0001$ \\
\hline$>80$ & 0.05 & 0.04 & 0.05 & $<0.0001$ \\
\hline \multicolumn{5}{|l|}{ Race/ethnicity } \\
\hline White & \multicolumn{4}{|c|}{ Reference category } \\
\hline Black & 0.94 & 0.84 & 1.05 & 0.27 \\
\hline Hispanic & 1.15 & 0.99 & 1.32 & 0.06 \\
\hline Other & 1.13 & 0.98 & 1.31 & 0.10 \\
\hline \multicolumn{5}{|l|}{ Year of cancer diagnosis } \\
\hline 2001 & \multicolumn{4}{|c|}{ Reference category } \\
\hline 2002 & 0.95 & 0.87 & 1.04 & 0.26 \\
\hline 2003 & 0.86 & 0.79 & 0.94 & $<0.001$ \\
\hline 2004 & 0.88 & 0.80 & 0.96 & $<0.01$ \\
\hline 2005 & 0.79 & 0.72 & 0.86 & $<0.0001$ \\
\hline \multicolumn{5}{|c|}{ Index of prior comorbidity score (NCI Comorbidity Index) } \\
\hline 0 & \multicolumn{4}{|c|}{ Reference category } \\
\hline 1 & 0.96 & 0.90 & 1.03 & 0.28 \\
\hline$\geq 2$ & 0.74 & 0.66 & 0.82 & $<0.0001$ \\
\hline \multicolumn{5}{|c|}{ Index of undetected comorbidity score } \\
\hline 0 & \multicolumn{4}{|c|}{ Reference category } \\
\hline 1 & 0.81 & 0.73 & 0.90 & $<0.0001$ \\
\hline$\geq 2$ & 0.38 & 0.30 & 0.49 & $<0.0001$ \\
\hline \multicolumn{5}{|l|}{ Indicators of poor performance } \\
\hline 0 & \multicolumn{4}{|c|}{ Reference category } \\
\hline$\geq 1$ & 0.56 & 0.51 & 0.62 & $<0.0001$ \\
\hline \multicolumn{5}{|l|}{ Stage at diagnosis } \\
\hline I & \multicolumn{4}{|c|}{ Reference category } \\
\hline II & 8.73 & 8.17 & 9.34 & $<0.0001$ \\
\hline III & 21.87 & 19.83 & 24.12 & $<0.0001$ \\
\hline \multicolumn{5}{|l|}{ Histological grade } \\
\hline Well differentiated & \multicolumn{4}{|c|}{ Reference category } \\
\hline Moderately differentiated & 1.58 & 1.44 & 1.72 & $<0.0001$ \\
\hline Poorly differentiated & 2.54 & 2.31 & 2.79 & $<0.0001$ \\
\hline Undifferentiated/anaplastic & 2.01 & 1.60 & 2.53 & $<0.0001$ \\
\hline Missing/unknown & 1.51 & 1.33 & 1.71 & $<0.0001$ \\
\hline \multicolumn{5}{|c|}{ Estrogen (ER) and progesterone $(\mathrm{PR})$ receptor status } \\
\hline ER and PR negative & \multicolumn{4}{|c|}{ Reference category } \\
\hline Either ER or PR positive & 0.32 & 0.29 & 0.35 & $<0.0001$ \\
\hline Both ER and PR positive & 0.24 & 0.22 & 0.26 & $<0.0001$ \\
\hline Unknown/missing & 0.30 & 0.27 & 0.34 & $<0.0001$ \\
\hline Percent in census tract with so & & & & \\
\hline$<25 \%$ & & & egory & \\
\hline$\geq 25 \%$ & 1.02 & 0.95 & 1.08 & 0.65 \\
\hline Percent in census tract living ir & & & & \\
\hline$<5 \%$ & & & egory & \\
\hline $5-7 \%$ & 0.93 & 0.85 & 1.02 & 0.13 \\
\hline $8-12 \%$ & 0.93 & 0.86 & 1.01 & 0.08 \\
\hline$>12 \%$ & 0.91 & 0.84 & 0.98 & 0.01 \\
\hline
\end{tabular}


TABLe 3: Continued.

\begin{tabular}{|c|c|c|c|c|}
\hline & \multirow{2}{*}{ OR } & \multicolumn{2}{|c|}{$95 \% \mathrm{CI}$} & \multirow{2}{*}{$P$ value } \\
\hline & & Lower & Upper & \\
\hline \multicolumn{5}{|l|}{ Type of geographic area } \\
\hline Large metropolitan & \multicolumn{4}{|c|}{ Reference category } \\
\hline Metropolitan & 1.12 & 1.05 & 1.20 & $<0.01$ \\
\hline Urban & 1.14 & 1.01 & 1.29 & 0.03 \\
\hline Less urban/rural & 1.06 & 0.95 & 1.18 & 0.32 \\
\hline
\end{tabular}

OR: Odds Ratio; CI: Confidence Interval.

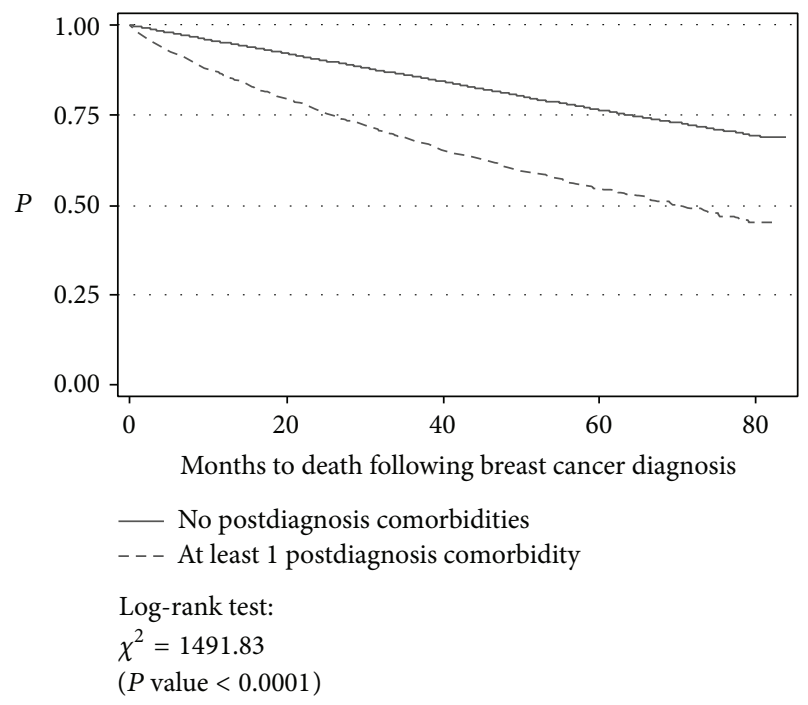

\begin{tabular}{lccccc}
\hline & \multicolumn{5}{c}{ Months following breast cancer diagnosis. } \\
& 0 & 20 & 40 & 60 & 80 \\
\hline Index of undetected comorbidity score $=0$ & & & & \\
$\quad$ Number at risk & 53,792 & 47,266 & 29,287 & 13,590 & 1,129 \\
$\quad$ Number of deaths in interval & 4,086 & 3,378 & 2,035 & 676 & NA \\
Index of undetected comorbidity score $\geq 1$ & & & & \\
$\quad$ Number at risk & 5,805 & 4,365 & 2,463 & 1,058 & 84 \\
$\quad$ Number of deaths in interval & 1,154 & 667 & 307 & 94 & NA \\
\hline
\end{tabular}

NA: not applicable

FIGURE 1: Unadjusted Survival.

[32] cancer and other conditions. The fact that effect sizes were larger for undetected conditions suggest that these may pose greater challenges for the healthcare team than those that have a history of being treated prior to cancer.

Undetected comorbidity also was associated with increased overall cancer and other-cause mortality. The impact on other-cause mortality was larger than on cancer mortality. However, all six HRs in the three survival analyses were highly statistically significant, and, in general, HRs for undetected comorbidity were larger than those for comorbidity detected prior to cancer. Again, this supports the hypothesis that undetected comorbidity may be more severe and that it may pose greater challenges to the healthcare team than conditions appearing in claims and, by implication, treated prior to cancer.
It is likely that the impact of undetected comorbidity on cancer mortality is partially explained by its direct impact on the likelihood of receiving adjuvant chemotherapy. The link between adjuvant chemotherapy and survival in breast cancer is well established, and adjuvant chemotherapy was not included in our survival analyses to avoid over adjustment of the models.

Our study has several limitations. First, as discussed above, we cannot rule out the possibility that unobserved factors may have confounded observed associations between the presence of undetected comorbidity and several of the observed risk factors, notably cancer stage at diagnosis. Second, both comorbidity indices in our study are based on claims and consequently have less-than-perfect sensitivity and specificity for the conditions of interest. Therefore, 


\begin{tabular}{|c|c|c|c|c|c|c|c|c|}
\hline 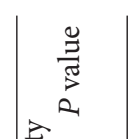 & 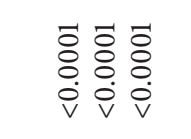 & $\stackrel{0}{\because} \stackrel{\overrightarrow{0}}{0} \dot{0}$ & 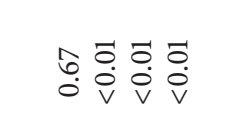 & $\begin{array}{l}\overrightarrow{0}: \overrightarrow{0} \\
\dot{0} \\
\dot{v} \dot{v}\end{array}$ & $\begin{array}{l}\vec{\delta} \overrightarrow{0} \\
\dot{0} \\
\dot{v} \dot{v}\end{array}$ & $\begin{array}{l}\vec{\Xi} \\
\dot{\mathrm{V}} \\
\mathrm{v}\end{array}$ & 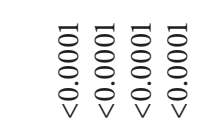 & 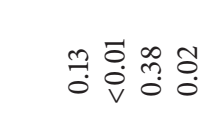 \\
\hline 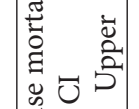 & 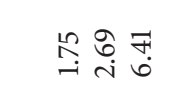 & 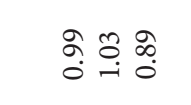 & 욱o̊ & $\vec{g}$ & 독 & तु̀ & 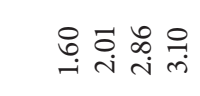 & $\stackrel{7}{7}$ \\
\hline 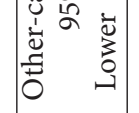 & 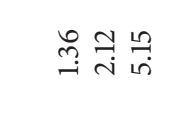 & 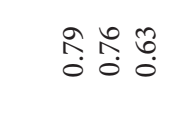 & 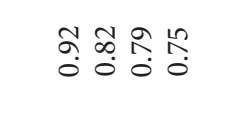 & 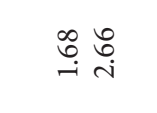 & 尔 & $\underset{\mathrm{i}}{\tilde{i}}$ & 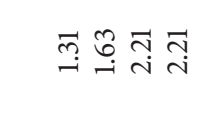 & \\
\hline 䍃 & 号 & $\begin{array}{l}\infty \\
\substack{\infty \\
0 \\
0} \\
0\end{array}$ & 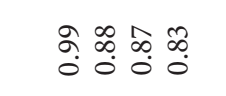 & $\stackrel{\substack{\infty \\
i}}{\infty}$ & $\stackrel{\infty}{\stackrel{\infty}{\rightarrow}} \overrightarrow{\mathrm{m}}$ & $\stackrel{n}{i}$ & 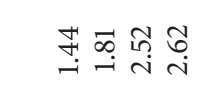 & \\
\hline 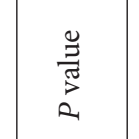 & 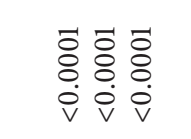 & 家 & 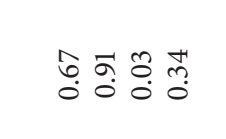 & $\begin{array}{l}\overrightarrow{0}: \overrightarrow{0} \\
\dot{0} \\
\dot{0} \dot{0} \\
\dot{v}\end{array}$ & $\begin{array}{l}\bar{\delta} \\
\dot{0} \\
\dot{0} \\
\dot{0} \\
\dot{0}\end{array}$ & $\begin{array}{l}\overrightarrow{0} \\
\dot{0} \\
\dot{0}\end{array}$ & 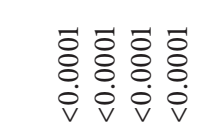 & : \\
\hline 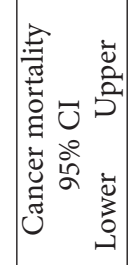 & 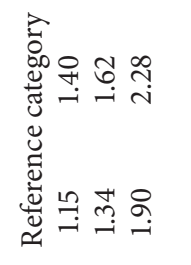 & 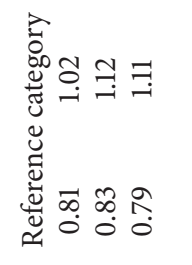 & 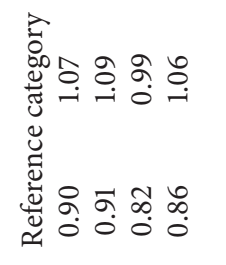 & 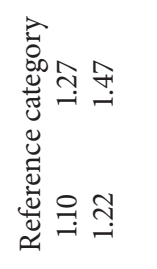 & 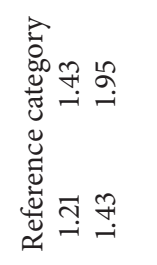 & 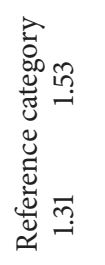 & 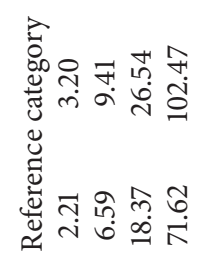 & 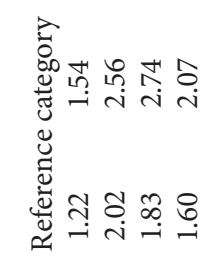 \\
\hline 舀 & 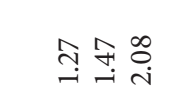 & Б̊ & 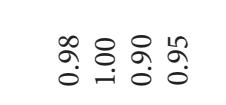 & $\stackrel{\infty}{\rightarrow} \stackrel{+}{\leftrightarrows}$ & $\stackrel{\widetilde{త}}{\rightarrow} \stackrel{0}{-}$ & $\underset{F}{F}$ & 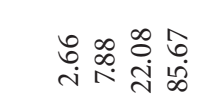 & \\
\hline 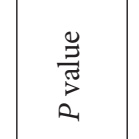 & 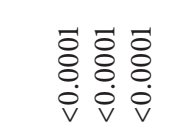 & 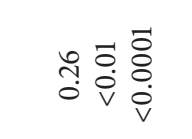 & ß̊. & 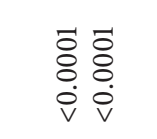 & 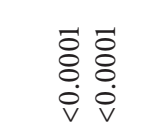 & $\begin{array}{l}\vec{\vdots} \\
\dot{0} \\
\dot{\vec{v}}\end{array}$ & 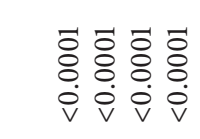 & \\
\hline 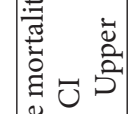 & 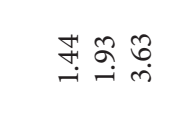 & $\exists \vec{s} \stackrel{\infty}{\circ}$ & 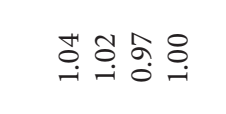 & 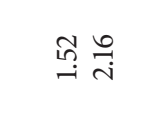 & $\stackrel{\Re}{\leftrightarrow} \underset{\rightarrow}{\stackrel{0}{i}}$ & $\stackrel{\infty}{\stackrel{\infty}{\rightarrow}}$ & 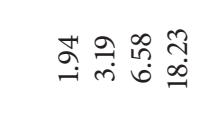 & \\
\hline $\mid$ & 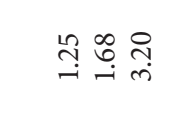 & 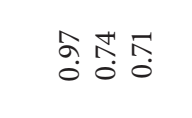 & तु. & 实吕 & $\stackrel{\infty}{\rightarrow} \underset{i}{i}$ & $\stackrel{-}{\stackrel{N}{=}}$ & 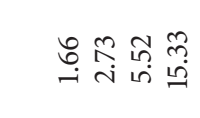 & \\
\hline 寽 & 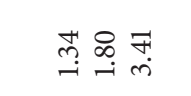 & 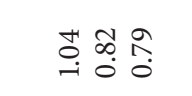 & ğ̊ă & 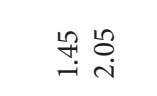 & 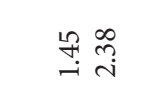 & $\stackrel{\infty}{\rightarrow}$ & فِئم & $\exists$ 哭 \\
\hline & $\underbrace{}_{0}$ & 总 & & 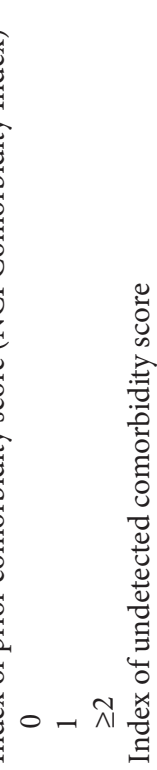 & 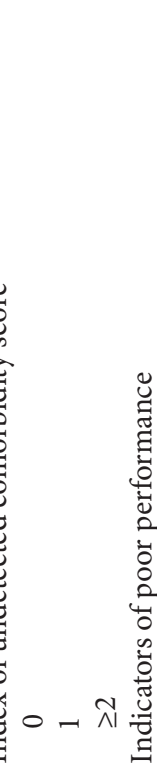 & 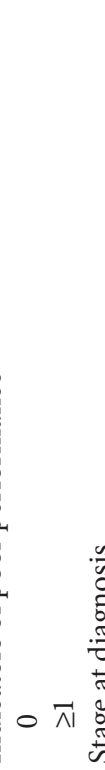 & 焉 & 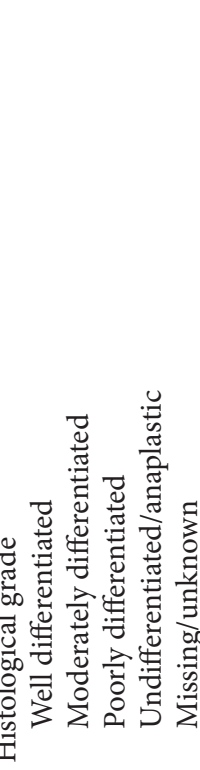 \\
\hline
\end{tabular}




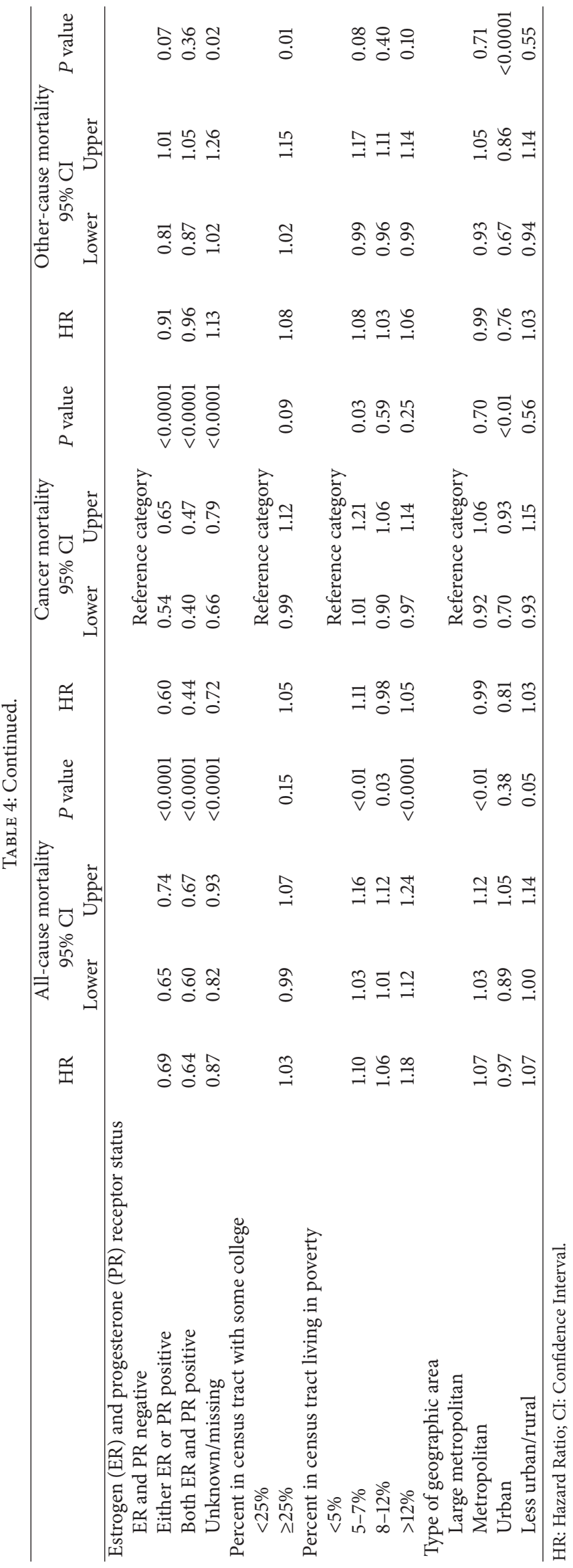


conditions that simply were not found in claims prior to cancer due to limitations of the algorithms in the NCI Comorbidity Index, but which actually had been detected and possibly treated at an earlier date, may have been misclassified as undetected. Third, since SEER includes only the month and not the day of cancer diagnosis, we elected to assign the first day of the month as the date of cancer diagnosis. Had we elected to assign the last day of the month, all conditions classified as previously undetected by virtue of first appearing in the month of cancer diagnosis would have been reclassified as previously detected.

\section{Conclusions}

Limitations notwithstanding, our findings indicate that those patients with established risk factors for poor outcomes in breast cancer, including advanced age, later stage, and poor performance status, also are at greatest risk for undetected comorbidity. Furthermore, undetected comorbidity appears to confer greater additional risk of poor outcomes than comorbidity detected prior to cancer, suggesting that it may be more severe and that it may pose additional challenges to the healthcare team. However, these hypotheses would require further investigation.

\section{Conflict of Interests}

The authors declare that there is no conflict of interests regarding the publication of this paper.

\section{Acknowledgments}

This study used the linked SEER-Medicare database. The interpretation and reporting of these data are the sole responsibility of the authors. The authors acknowledge the efforts of the Applied Research Program, NCI; the Office of Research, Development and Information, CMS; Information Management Services (IMS), Inc.; and the Surveillance, Epidemiology, and End Results (SEER) Program tumor registries in the creation of the SEER-Medicare database. Editorial assistance in this paper was provided by Kim Merjan and Suzanne Griffiths.

\section{References}

[1] R. Yancik, M. N. Wesley, L. A. G. Ries, R. J. Havlik, B. K. Edwards, and J. W. Yates, "Effect of age and comorbidity in postmenopausal breast cancer patients aged 55 years and older," Journal of the American Medical Association, vol. 285, no. 7, pp. 885-892, 2001.

[2] X. Du and J. S. Goodwin, "Patterns of use of chemotherapy for breast cancer in older women: findings from medicare claims data," Journal of Clinical Oncology, vol. 19, no. 5, pp. 1455-1461, 2001.

[3] W. J. Louwman, M. L. G. Janssen-Heijnen, S. Houterman et al., "Less extensive treatment and inferior prognosis for breast cancer patient with comorbidity: a population-based study," European Journal of Cancer, vol. 41, no. 5, pp. 779-785, 2005.
[4] A. Hawfield, J. Lovato, D. Covington, and G. Kimmick, "Retrospective study of the effect of comorbidity on use of adjuvant chemotherapy in older women with breast cancer in a tertiary care setting," Critical Reviews in Oncology/Hematology, vol. 59, no. 3, pp. 250-255, 2006.

[5] S. H. Giordano, Z. Duan, Y.-F. Kuo, G. N. Hortobagyi, and J. S. Goodwin, "Use and outcomes of adjuvant chemotherapy in older women with breast cancer," Journal of Clinical Oncology, vol. 24, no. 18, pp. 2750-2756, 2006.

[6] M. A. Schonberg, E. R. Marcantonio, D. Li, R. A. Silliman, L. Ngo, and E. P. McCarthy, "Breast cancer among the oldest old: tumor characteristics, treatment choices, and survival," Journal of Clinical Oncology, vol. 28, no. 12, pp. 2038-2045, 2010.

[7] T. S. Field, J. L. F. Bosco, M. N. Prout et al., "Age, comorbidity, and breast cancer severity: impact on receipt of definitive local therapy and rate of recurrence among older women with earlystage breast cancer," Journal of the American College of Surgeons, vol. 213, no. 6, pp. 757-765, 2011.

[8] L. H. Land, S. O. Dalton, T. L. Jørgensen, and M. Ewertz, "Comorbidity and survival after early breast cancer. A review," Critical Reviews in Oncology/Hematology, vol. 81, no. 2, pp. 196205, 2012.

[9] A. Berglund, A. Wigertz, J. Adolfsson et al., "Impact of comorbidity on management and mortality in women diagnosed with breast cancer," Breast Cancer Research and Treatment, vol. 135, no. 1, pp. 281-289, 2012.

[10] S. Houterman, M. L. G. Janssen-Heijnen, C. D. G. W. Verheij et al., "Comorbidity has negligible impact on treatment and complications but influences survival in breast cancer patients," British Journal of Cancer, vol. 90, no. 12, pp. 2332-2337, 2004.

[11] G. Nagel, U. Wedding, H. Hoyer, B. Röhrig, and D. Katenkamp, "The impact of comorbidity on the survival of postmenopausal women with breast cancer," Journal of Cancer Research and Clinical Oncology, vol. 130, no. 11, pp. 664-670, 2004.

[12] C. M. Tammemagi, D. Nerenz, C. Neslund-Dudas, C. Feldkamp, and D. Nathanson, "Comorbidity and survival disparities among black and white patients with breast cancer," Journal of the American Medical Association, vol. 294, no. 14, pp. 17651772, 2005.

[13] N. Siegelmann-Danieli, V. Khandelwal, G. C. Wood et al., "Breast cancer in elderly women: outcome as affected by age, tumor features, comorbidities, and treatment approach," Clinical Breast Cancer, vol. 7, no. 1, pp. 59-66, 2006.

[14] D. P. Cronin-Fenton, M. Nørgaard, J. Jacobsen et al., "Comorbidity and survival of Danish breast cancer patients from 19952005," British Journal of Cancer, vol. 96, pp. 1462-1468, 2007.

[15] D. P. Cronin-Fenton, M. Nørgaard, J. Jacobsen et al., "Comorbidity and survival of Danish breast cancer patients from 1995 to 2005," British Journal of Cancer, vol. 96, no. 9, pp. 1462-1468, 2007.

[16] T. P. Ahern, L. Lash, S. Thwin, and A. Silliman, "Impact of acquired comorbidities on all-cause mortality rates among older breast cancer survivors," Medical Care, vol. 47, no. 1, pp. 73-79, 2009.

[17] M. A. Schonberg, E. R. Marcantonio, L. Ngo, D. Li, R. A. Silliman, and E. P. McCarthy, "Causes of death and relative survival of older women after a breast cancer diagnosis," Journal of Clinical Oncology, vol. 29, no. 12, pp. 1570-1577, 2011.

[18] S. Yasmeen, G. Xing, C. Morris, R. T. Chlebowski, and P. S. Romano, "Comorbidities and mammography use interact to explain racial/ethnic disparities in breast cancer stage at diagnosis," Cancer, vol. 117, no. 14, pp. 3252-3261, 2011. 
[19] J. L. Patnaik, T. Byers, C. DiGuiseppi, D. Dabelea, and T. D. Denberg, "Cardiovascular disease competes with breast cancer as the leading cause of death for older females diagnosed with breast cancer: a retrospective cohort study," Breast Cancer Research, vol. 13, no. 3, article R64, 2011.

[20] J. L. Patnaik, T. Byers, C. Diguiseppi, T. D. Denberg, and D. Dabelea, "The influence of comorbidities on overall survival among older women diagnosed with breast cancer," Journal of the National Cancer Institute, vol. 103, no. 14, pp. 1101-1111, 2011.

[21] L. H. Land, S. O. Dalton, M.-B. Jensen, and M. Ewertz, "Impact of comorbidity on mortality: a cohort study of 62,591 Danish women diagnosed with early breast cancer, 1990-2008," Breast Cancer Research and Treatment, vol. 131, no. 3, pp. 1013-1020, 2012.

[22] D. Braithwaite, D. H. Moore, W. A. Satariano et al., "Prognostic impact of comorbidity among long-term breast cancer survivors: results from the LACE study," Cancer Epidemiology, Biomarkers \& Prevention, vol. 21, no. 7, pp. 1115-1125, 2012.

[23] C. N. Klabunde, A. L. Potosky, J. M. Legler, and J. L. Warren, "Development of a comorbidity index using physician claims data," Journal of Clinical Epidemiology, vol. 53, no. 12, pp. 12581267, 2000.

[24] M. E. Charlson, P. Pompei, K. A. Ales, and C. R. MacKenzie, "A new method of classifying prognostic comorbidity in longitudinal studies: development and validation," Journal of Chronic Diseases, vol. 40, no. 5, pp. 373-383, 1987.

[25] M. D. Danese, C. O’Malley, K. Lindquist, M. Gleeson, and R. I. Griffiths, "An observational study of the prevalence and incidence of comorbid conditions in older women with breast cancer," Annals of Oncology, 2011.

[26] J. L. Warren, C. N. Klabunde, D. Schrag, P. B. Bach, and G. F. Riley, "Overview of the SEER-Medicare data: content, research applications, and generalizability to the United States elderly population," Medical Care, vol. 40, no. 8, pp. IV-3-IV-18, 2002.

[27] A. Fritz and L. Ries, Eds., SEER Program Code Manualed, Cancer Statistics Branch, Surveillance Program, Div of Cancer Control and Pop Sciences, National Cancer Institute, National Institutes of Health, Public Health Service, U.S. Department of Health and Human Services, Bethesda, Md, USA, 3rd edition, 1998.

[28] A. J. Davidoff, M. Tang, B. Seal, and M. J. Edelman, "Chemotherapy and survival benefit in elderly patients with advanced nonsmall-cell lung cancer," Journal of Clinical Oncology, vol. 28, no. 13, pp. 2191-2197, 2010.

[29] National Cancer Institute, Procedure Codes For SEER Medicare Analysis, National Cancer Institute, Bethesda, Md, USA, 2010.

[30] N. L. Keating, M. B. Landrum, J. Z. Ayanian, E. P. Winer, and E. Guadagnoli, "The association of ambulatory care with breast cancer stage at diagnosis among medicare beneficiaries," Journal of General Internal Medicine, vol. 20, no. 1, pp. 38-44, 2005.

[31] M. E. Gornick, P. W. Eggers, and G. F. Riley, "Associations of race, education, and patterns of preventive service use with stage of cancer at time of diagnosis," Health Services Research, vol. 39, no. 5, pp. 1403-1427, 2004.

[32] B. B. Barone, H.-C. Yeh, C. F. Snyder et al., "Long-term all-cause mortality in cancer patients with preexisting diabetes mellitus: a systematic review and meta-analysis," Journal of the American Medical Association, vol. 300, no. 23, pp. 2754-2764, 2008. 


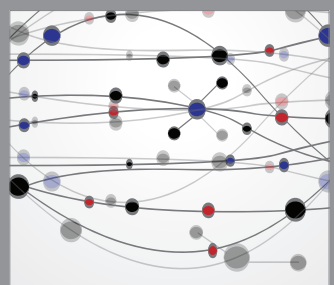

The Scientific World Journal
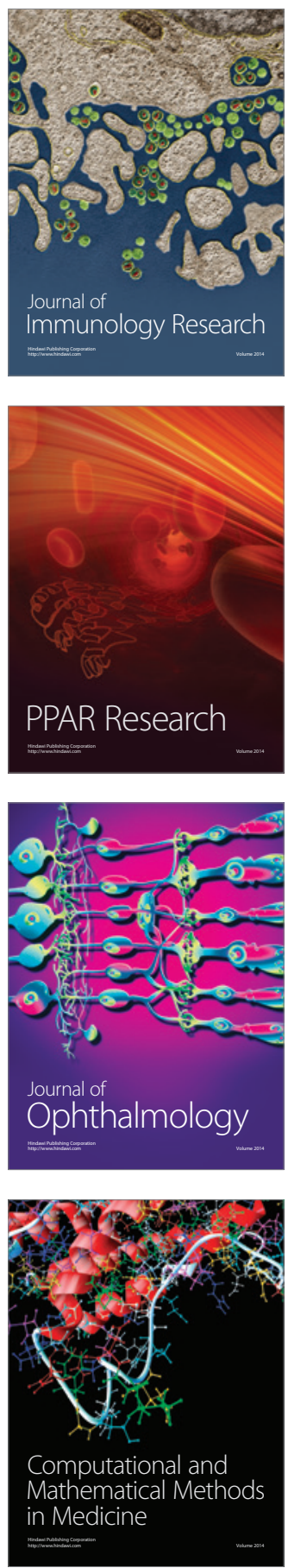

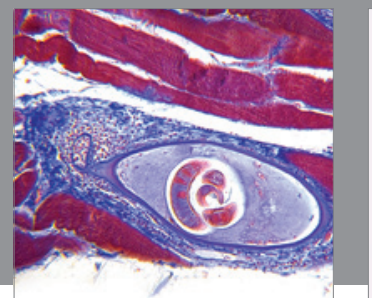

Gastroenterology

Research and Practice
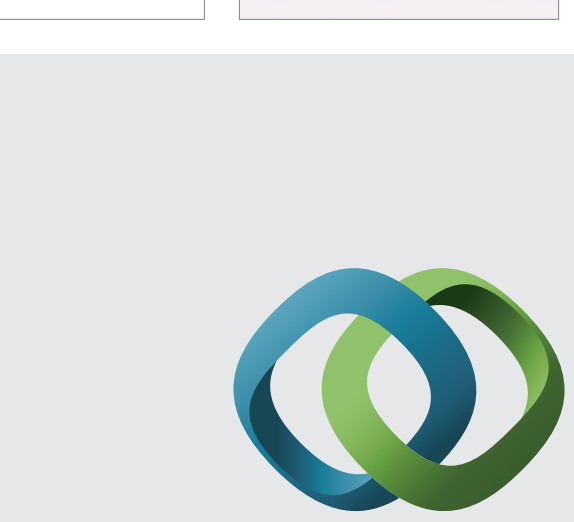

\section{Hindawi}

Submit your manuscripts at

http://www.hindawi.com
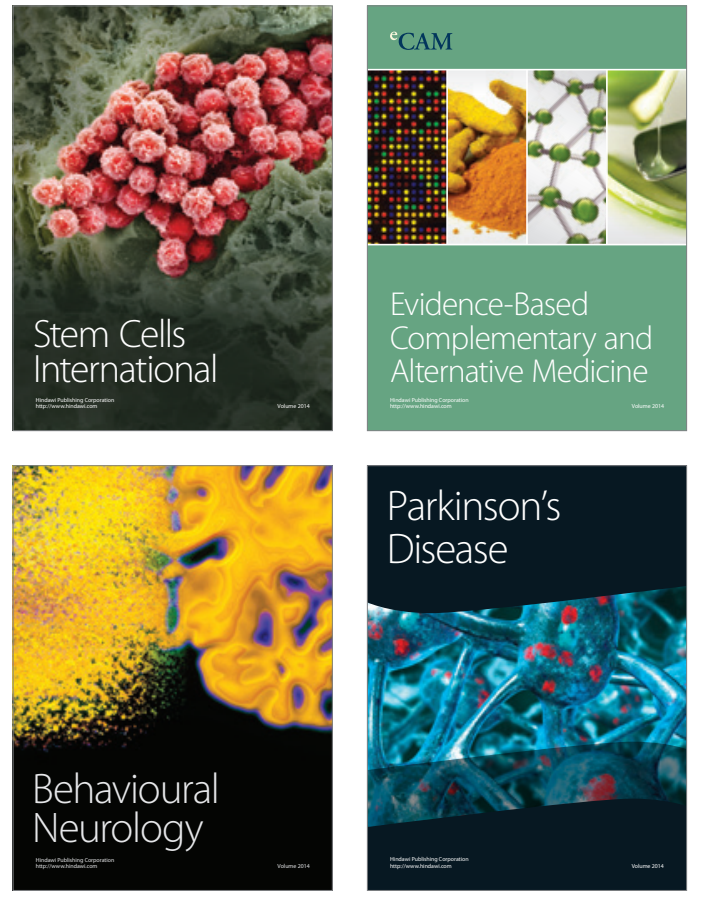
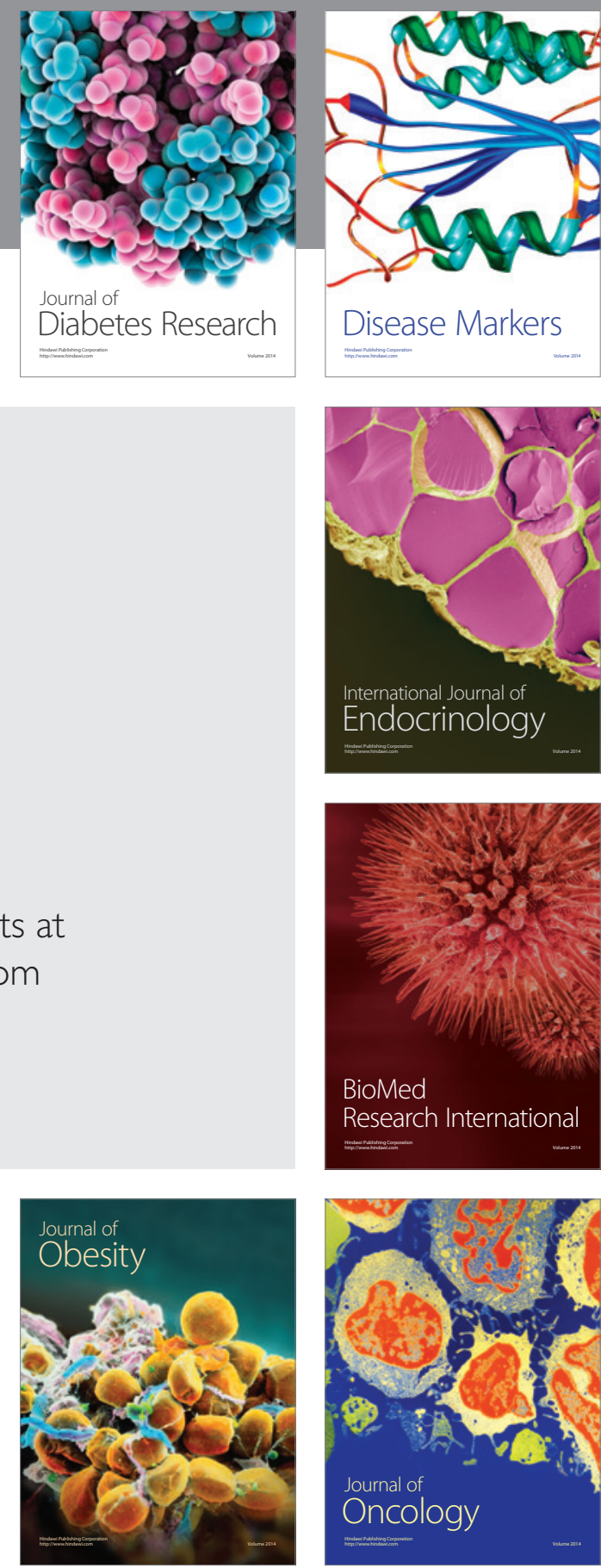

Disease Markers
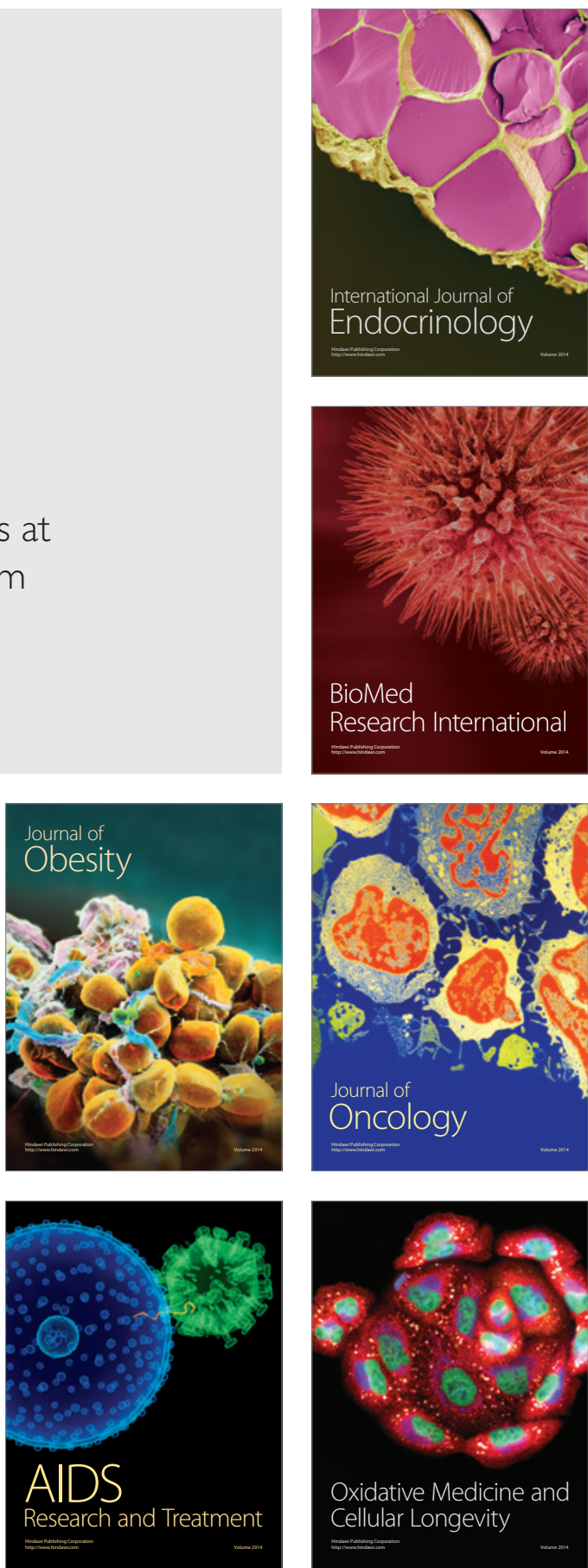